\title{
Management analysis of the logistics support system-of-systems of US aircraft carrier formation
}

\author{
Qin $\mathrm{Wu}^{1}, \mathrm{Min} \mathrm{Wu}^{2}$, Yunzhou Sun ${ }^{3, \mathrm{a}^{*}}$ \\ ${ }^{1}$ Department of Management Engineering and Equipment Economics.Naval University of Engineering Wuhan 430033, China \\ ${ }^{2}$ Department of Management and Economics Xinzhou Vocational School Wuhan 430033, China \\ ${ }^{3}$ Hubei functional fiber processing and testing Engineering Technology Research Center Wuhan Textile University Wuhan 430073, \\ China
}

\begin{abstract}
The US aircraft carrier formation is a complex system-of -systems (SoS). Taking the logistics support organization system of the U.S. aircraft carrier as an example, the scientific management of logistics support SoS is discussed in this paper. Through the detailed discussion and analysis of the command relationship of the US aircraft carrier logistics support organization, as well as the discussion of the responsibility relationship of the U.S. aircraft carrier logistics support organization and its various agencies, the organization and command mode of US aircraft carrier logistics support are discussed. The management characteristics of US aircraft carrier logistics support organization SoS are summarized in detail.
\end{abstract}

\section{INTRODUCTION}

In ancient China, there is a saying that an army marches on its stomach. Since ancient times, logistics support is the material basis for winning the war. Therefore, the smooth logistics support system restricts the generation of support and combat effectiveness. In recent years, the U.S. military has introduced modern scientific management methods, such as system theory, cybernetics and information theory, into the field of logistics management, and has established mechanism systems in different service fields to meet the needs of different logistics management. Especially in the logistics support system, the application of various efficient mechanisms and systems has effectively promoted the improvement of support ability and provided a strong guarantee for the victory of the war. For the construction of equipment support system-of- systems (SoS) in the world, it is of great significance to study and analyze the U.S. logistics support SoS and learn from its beneficial experience.

Generally speaking, SoS is a collection of taskoriented or dedicated systems that pool their resources and capabilities together to create a new, more complex system which offers more functionality and performance than simply the sum of the constituent systems. Currently, systems of systems is a critical research discipline for which frames of reference, thought processes, quantitative analysis, tools, and design methods are incomplete[1]. The method of defining, abstracting, modeling and analyzing system of systems problems is often called system-of-systems engineering. SoS engineering (SoSE) originates from system engineering (SE), but it is different from system engineering because they are the study of problems in different fields. SoS engineering is the evolution and expansion of system engineering, which mainly solves the system problems that cannot be solved by system engineering. In the field of modern military information superiority, SoS is considered to connect the system to the joint system of systems, which can realize the interoperability and coordination of command, control, computers, communications and information (C4I) and intelligence, surveillance and reconnaissance (ISR) systems [2]. Or it can be understood as a method to pursue system development, integration, interoperability and optimization to improve the performance of future battlefield scenarios [3].

The U.S. Navy aircraft carrier formation (ACF) is the most basic form of force organization of the U.S. Navy, and the carrier logistics organization and command has become the core part of the U.S. Navy Logistics Organization and command. After years of construction and practice, the U.S. Navy ACF has built a more efficient command system, a perfect organization, appropriate command mode and advanced command system, and formed a relatively complete logistics organization SoS. ACF is considered to be a typical and complex SoS [4]. In this paper, the U.S. aircraft carrier logistics support SoS is taken as an example to analyze the general situation, management mechanism and it's characteristics.

\section{ORganization AND COMMAND RELATIONSHIP OF US AIRCRAFT CARRIER LOGISTICS SUPPORT}

The U.S. military adopts a command system of separation of government and order. The construction and

\footnotetext{
*Corresponding author: syz1979@163.com
} 
management of the armed forces are in the charge of various services, and the Joint Staff is responsible for the deployment and command of the armed forces in wartime. In the daily patrol and training of US Navy ACF, it is usually a mixed formation. Formation ships include surface combat vessels, auxiliary ships and submarines. In wartime, ACF may also include ships from other battlefields, such as mixing ships from the Atlantic Fleet with those from the Pacific Fleet. Therefore, the ACF is also called the task force formation (TFF). Although the size and strength of the U.S. Navy ACF often change according to operational needs, the formation combat command system and logistics organization and command system are relatively fixed. Moreover, under the leadership of the United States military joint operations command system, the logistics organization and command system of the US Navy ACF has also achieved a high degree of integration.

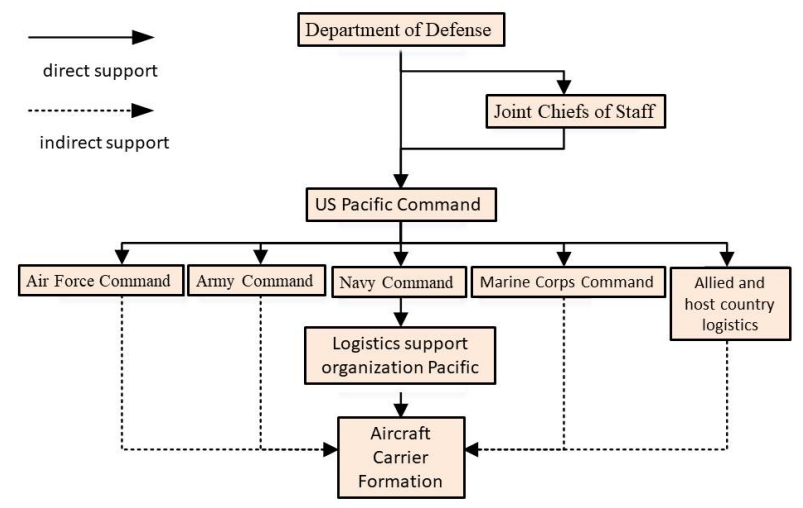

Figure 1. Organization structure of logistics support for ACF of U.S. Navy Pacific Fleet.

The logistics construction and management of the U.S. Navy is mainly in the charge of the headquarters of the Secretary of the Navy, such as the naval supply system command. At present, the oil and transportation services are supplied by the joint service department of the three services, and the other service support of the naval ship troops is in the charge of the Navy Department. Under the influence of the US military's global strategy, the US Navy aircraft carrier is responsible for the global deployment and global combat tasks. Therefore, the logistics support of the aircraft carrier, especially in the overseas underdeveloped areas or without reliable supply bases, must be supported by the theater command through the unified deployment of the three services' logistics forces, the Allied forces and the host country's logistics forces. The logistics support organization structure of carrier formation of US Navy Pacific fleet is shown in Fig. 1.

At present, the U.S. military has divided its local and global headquarters into five regional headquarters for operational management, including the northern headquarters, the southern headquarters, the Pacific headquarters, the European headquarters and the central headquarters. In wartime, when an aircraft carrier formation is deployed to a sea area that is not the carrier's responsibility, its logistics support is arranged by the regional headquarters of the sea area where it is located.
For example, during the Iraq war, when the carrier strike groups of the Pacific Fleet and the Atlantic Fleet entered the Indian Ocean to carry out combat tasks, the central logistics support headquarters was responsible for unified command and control. At this time, the logistics organizations and forces of the Navy Department were dispatched by the naval command of the central headquarters. When the ACF needs support from the allies and the host country, it is coordinated by the corresponding regional headquarters. The naval command and the Fifth Fleet Command and its logistics command organization are located in Bahrain. It is mainly responsible for the unified command and support of all maritime forces deployed in the Mediterranean Sea, the Red Sea and the Persian Gulf.

\section{U.S. AIRCRAFT CARRIER LOGISTICS SUPPORT ORGANIZATION}

The logistics support organization of US Navy aircraft carrier formation is composed of three parts. The first part is shore based logistics support organization, the second part is maritime logistics support organization, and the third part is carrier on-board logistics support organization.

\subsection{Shore based logistics support organization of regional headquarters or fleet}

The U.S. aircraft carrier shore based logistics support organization (logistics commander) mainly includes:

\subsubsection{Commander / Logistics Deputy Commander (Regional Command)}

They are mainly responsible for logistics planning, resource allocation, command and coordination of wartime formations.

\subsubsection{Fleet Commander (e.g. Pacific and Atlantic Fleet Commander).}

They are mainly responsible for formulating relevant policies and standards for logistics support, coordinating logistics related activities, issuing operational logistics support orders, and organizing implementation and inspection.

\subsubsection{Deputy Commander (Fleet Logistics)}

To be responsible for the logistics support business of the whole fleet's ships and shore based forces, command the shore service departments and supply ships to replenish the combat forces, assist the fleet commander and the ship type commander to implement the instructions and plans related to logistics work, and coordinate the oil supply and mail service of the naval forces within the jurisdiction of the fleet. In addition, he is also responsible for supervising the financial work of the whole fleet and 
adjusting the medical staff and medical equipment of the fleet.

\subsubsection{Fleet Logistics Officer}

Under the leadership of the fleet commander and the deputy commander of fleet logistics, he is responsible for the work of the logistics joint office within the fleet general staff.

\subsubsection{Supply staff office (Fleet Command)}

The organization is responsible for providing suggestions on logistics support to the fleet commander, ensuring the consistency of the fleet with the instructions of the superior, and providing the work of the logistics department of the fleet and the replenishment activities of the replenishment ships. Implement supervision and inspection, and be responsible for reviewing and undertaking the supply application forms to be submitted.

\subsection{Maritime logistics support organization of ACF}

\subsubsection{Formation Commander / Deputy Logistics Commander}

Their responsibilities are mainly responsible for the logistics support, organization and command of the whole formation, issuing support and supply orders, and determining the support opportunity and sea area. In addition, they are also responsible for the anti- submarine, air defense and other operational command work of the whole formation in the process of formation support and supply, as well as other logistics command work.

\subsubsection{Staff Office of Formation Commander}

The organization is responsible for providing advice on logistics support to the formation commander and Deputy logistics commander. Other tasks mainly include supervising and implementing the logistics support activities of formation, coordinating the affairs between the supply ship and the ship to be supplied, supervising and inspecting the replenishment activities, and reviewing and undertaking the supply application forms to be reported.

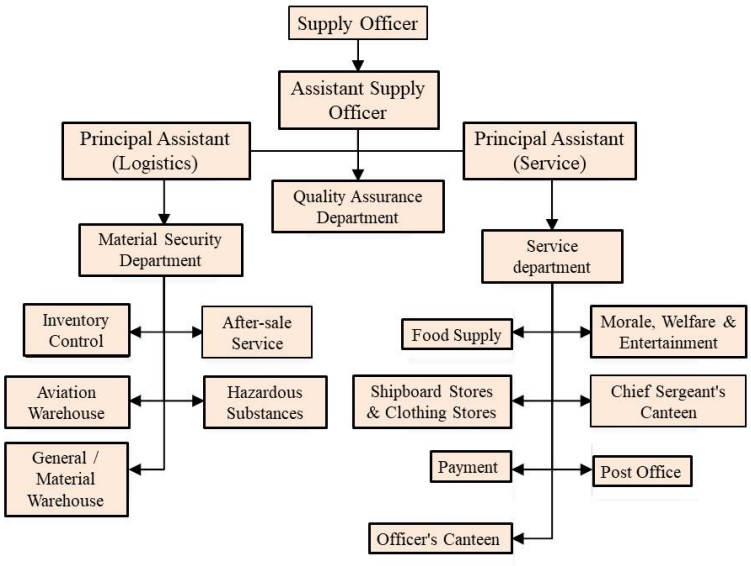

Figure 2. Logistics support organization structure of US Navy aircraft carrier.

\subsection{Logistics support organization on aircraft carrier}

The shipboard logistics department is the basic Department of the U.S. Navy aircraft carrier logistics support system, and the shipboard supply department is the main logistics organization and command organization.

The administrative organization of the shipboard supply department is composed of the leaders and staff members of the supply department. They are led by the shipboard supply officer, who is also the top officer of the supply department. The supply officers on board have three main assistants, namely, the assistant of supply officer(ASO), the principal assistant of logistics (PAL) and the principal assistant of service (PAS). The main functions of shipboard supply department are divided into material support and service support. Material support includes shipboard consumables, equipment, spare parts, inert nuclear weapons materials and corresponding other items, such as fuel, maps, consumables. Service support includes meal preparation and service management of the restaurant, and the management of ship shops, vending machines, laundry, Barber Room and other related facilities. The logistics support organization structure of the US Navy aircraft carrier is shown in Fig.2.

\section{ORgANIZATION AND COMMAND MODE OF US AIRCRAFT CARRIER LOGISTICS SUPPORT SOS}

According to the operational area and mission, the command mode of the U.S. aircraft carrier logistics support organization SoS is usually divided into two categories.

\subsection{Joint command of regional headquarters and fleet}

ACF usually carry out joint operations under the unified command of regional headquarters. Therefore, in wartime, the regional commander commands all combat forces including aircraft carrier battle group. Under the 
guidance of the regional commander and logistics deputy commander, the fleet commander and logistics deputy commander specifically conduct the command of the aircraft carrier and its formation logistics support activities.

\subsection{Independent organization and command of ACF}

Carrier independent command refers to the logistics support activities of each ship in the formation under the command of the commander of ACF. This situation is usually used for peacetime training and cruising, or wartime combat area is close to the logistics base, shortterm deployment, low frequency of carrier based aircraft, and less consumption of fuel, ammunition and supplies. A deployment or operation can be completed only by relying on the large-scale integrated supply ship in the formation for accompanying supply.

\section{THE MANAGEMENT CHARACTERISTICS OF US AIRCRAFT CARRIER LOGISTICS SUPPORT ORGANIZATION SOS}

\subsection{Separation of government and decree, relative independence of utilization and management}

The U.S. Navy believes that the logistics organization and command system is the most important factor related to aircraft carrier combat effectiveness. Therefore, the U.S. Navy separates the carrier logistics support organization command from the logistics construction, and integrates the carrier logistics organization and command into the military order system of operational management, which is organized and directed by the operational commander of the regional command. The naval department is responsible for the logistics construction of aircraft carriers, which is included in the military and political system. The construction and utilization of the system is relatively separate, so that the aircraft carrier forces only need to put forward the logistics support requirements, and do not need to consider how to obtain and plan logistics support resources and other complex work. In this way, the formation can concentrate on operations.

\subsection{Simplified hierarchy, flexible organization and command mode}

According to the level from high to low, the logistics organization of US aircraft carrier and its formation can be divided into three parts: regional headquarters, fleet formation and aircraft carrier formation. Each part contains many support and command departments. However, from the actual operation process, the four levels of "regional headquarters, naval command of regional headquarters, fleet logistics support organization, aircraft carrier formation" can be simplified into three levels of "maritime force support organization of regional headquarters, fleet logistics support organization, aircraft carrier formation". It can even be simplified into two levels of "maritime force support organization of regional headquarters and aircraft carrier formation". The whole process is less, and the support and command efficiency is high. According to the deployment area, deployment time and mission intensity of ACF, the U.S. Navy flexibly adopts two different command modes: joint command and independent command of regional headquarters and fleet. This command mode not only ensures the effectiveness of logistics command in largescale campaign operations, but also ensures the simplicity of logistics command in cruise training.

\subsection{The logistics system is embedded in the combat command system, with high informatization}

The U.S. aircraft carrier logistics system is based on the Navy subsystem of the U.S. Global Combat Support System (GCSS). The US GCSS and the US global combat command system are based on the same communication and data processing platform. In other words, the carrier logistics organization and command system is fully integrated into the combat command system. In this way, the logistics organization and command system of ACF and its support forces can be constructed. This system can connect combat, joint logistics and civilian forces, thus ensuring information fusion and integration between logistics and operations.

The logistics support organization and command system of US Navy ACF is a real-time communication system based on the flagship data display system (FDDS). The FDDS is a tactical command system for the US Navy equipped with ACF at the end of last century. As the development and improvement of the US Navy tactical flagship command center (TFCC), the system is also the most important command platform on the US Navy aircraft carrier, with very powerful functions. The flagship data display system (FDDS) can exchange data and information with various communication system interfaces, such as officer-in-tactical command information exchange subsystem (OTCIXS), tactical data information exchange system (TADIXS), 4A data link, 11 data link, 16 data link and 22 data link. The use of these advanced real-time communication information systems has realized the information fusion and integration between US aircraft carrier operations and logistics. It has improved the use efficiency of U.S. logistics materials and support forces. It also provides information support for US aircraft carrier to form efficient logistics support capability.

\section{Conclusions}

In this paper, taking the U.S. aircraft carrier logistics support SoS as an example, we discuss the scientific management of logistics support system. We have a detailed discussion and Analysis on the organization and command relationship of US aircraft carrier logistics 
support. In this paper, the responsibilities of the U.S. aircraft carrier logistics support SoS and its organizations are discussed. At the same time, the organization and command mode of US aircraft carrier logistics support is also discussed. Finally, the characteristics of the U.S. aircraft carrier logistics support organization SoS are summarized in detail.

\section{REFERENCES}

1. M. Jamshidi, "System of Systems Engineering-A Definition," IEEE SMC 2005, pp.10-12, Oct. 2005.

2. V. Kotov, "System-of-Systems as Communicating Structures," Hewlett Packard Computer Systems Laboratory Paper HPL-97-124, pp. 1-15,1997.

3. D. DeLaurentis, "Research Foundations," School of Aeronautics and Astronautics, Purdue University, West Lafayette, IN, 2007.

4. K.M. Adams, T.J. Meyers, "The US Navy carrier strike group as a system of systems," Int. J. System of Systems Engineering, vol.2, pp.91-97, 2011. 